\title{
MODELLING AND FORECASTING VEHICLE REGISTRATION SYSTEM: AN ARMA APPROACH
}

\author{
D. A. Agunbiade ${ }^{1}$ and E.N. Peter ${ }^{2}$ \\ ${ }^{1}$ Department of Mathematical Sciences, Olabisi Onabanjo University, Nigeria. \\ ${ }^{2}$ Ministry of Transportation, Lagos State
} Keywords: ARMA model, Vehicle Registration, Vehicle Ownership, Vehicle Type, Stationary Time
Series Process.

\begin{abstract}
The role of transportation in the promotion of national unity and socio- economic integration in Nigeria cannot be overemphasized. Transport stimulates a sense of oneness multi understanding in the cultural diversification of the most populous nation in the sub Sahara of African Continent. it is therefore of interest to study using the Autoregressive Moving Average, the transportation system in Nigeria using Lagos State (being the commercial centre) and also maintains a robust data base through the AUTOREG System as a case study by modeling and forecasting the Vehicle registration system in terms of types and ownership. The result of the Autoregressive Moving Average (ARMA) approach indicated that there is tendency for an increase in the registration of Vehicles in the future.

It is therefore suggested that to accommodate an increase in the number of Vehicles registration, a robust Vehicle database should be designed across the country for security, research and adequate planning; and Nigerian government at all levels should strive to provide adequate and reliable road network system to meet this emerging developmental activities among others.
\end{abstract}

\section{Introduction}

The need for movement of people, goods, ideas and services has made transport provision and its management an issue to reckon with by every successive government of the federation in Nigeria. The survival of the nation relies heavily on the effectiveness of its transportation system. With growth and development, the intensive use to which roads and vehicles are subjected has increased tremendously and it can be observed that the road transport account for more commodity movement within Nigeria than any other mode of transportation.

It is a public opinion that the role of transportation in the promotion of national unity and socioeconomic integration cannot be overemphasized. Transport stimulates a sense of oneness and multi understanding, in the cultural diversification society. It should be noted that labor mobility and elimination of unemployment or artificial shortage of labour and materials could be greatly improved with safer, cheaper, more accessible and more comfortable transport facilities. This study therefore is set: (i) To examine the inherent characteristics of Motor Vehicles registration data in Lagos State for the past twenty years and then forecast for future values which will enable the government to plan for transportation in Lagos State of Nigeria (ii) To examine the existing situation of transportation system in Nigeria as well as Lagos State, (iii) To examine the impact of the involvement of private participation in vehicles registration in Lagos State (AUTOREG) (iv) And then forecast for future values which will enable the Government to plan for transportation in Lagos State of Nigeria.

Since the study by Box and Jenkins (1976), time series analysis has been popularly adopted for the modeling of dependent, sequential observation. Two useful representations express the behaviour of observed time series processes, namely, the autoregressive (AR) and the moving average (MA), which describe the behaviour of stochastic and dynamic systems (Box et al., 1994). Time series analysis has outperformed other forecasting models because of its well-established theoretical foundation and the ease of estimation (Karlaftis and Vlahogianni, 2009) and its value regardless of 
a stationary or non stationary time series, and with or without seasonal components (Lim and McAleer, 2002). It has therefore been successfully and overwhelmingly applied for modeling and forecasting in the transportation management literature, such as air transportation (Inglada and Rey, 2004), safety issues (McLeod and Vingilis, 2008), the modeling of freight and transportation demand (Batchelor et al., 2007), and air quality and transportation emissions (Lau et al., 2009).

Intervention analysis is a transfer function stochastic model and may be understood as an extension to the ARIMA set of time series models. In terms of intervention, such an analysis has been used to study the impact of exceptional external events, including natural disasters, political or economic policy initiatives or changes, technological changes, strikes, sales promotions, advertising and the likes (Liu, 2006). Box and Tiao (1975) provided a procedure, known as intervention analysis, for analyzing a time series in the presence of external events. It exhibits a useful stochastic modelling tool that can rigorously analyze the impact and represent two distinct components: an underlying disturbance term and the set of interventions in the series.

The pioneering application of intervention analysis was a study by Box and Tiao (1975), which provided an analytical framework for examining the effect of two interventions in Los Angeles: the opening of the Golden State Freeway, and the enforcement of a new law concerning oxidant data. Over the years, the technique has been widely employed and successfully applied in different fields in the physical and social sciences.

Although intervention analysis has been well-documented in various disciplines, this approach has not attracted much attention from researchers and academics in air travel demand. One study by Coshall (2003) applied the intervention model to assessing the impact of three interventions - the U.S. bombing of Libya in 1986, the Lockerbie air disaster in 1988, and the Persian Gulf crisis during 1990-1991 on the flow of U.K. air passengers to a variety of destinations. Lee et al. (2005) employed intervention analysis to assess the status of recovery after the September 11th terrorist attacks on US air passenger transport demand. Empirical results showed that the demand for US air passenger transport had not yet fully recovered from the attacks but the demand had appeared to be increasing gradually. In Pitfield (2007), the ARMA with intervention model was used to examine the influence of airline alliances on the traffic of constituent airlines for five routes to the US from European hubs (Frankfurt and Paris). A similar methodology was applied by Pitfield (2008) to estimate the impact of the so-called "Southwest Effect" on traffic and market share for key domestic air routes in the USA, where Southwest had started its service. Lai and Lu (2005) compared the SARMA with intervention model with different techniques; the results showed that it outperformed all other techniques when significant intervention in the series existed. Efforts are made in this research to incorporate the intervention analysis of the ARMA approach to study the Vehicular registration system in the Lagos State of Nigeria.

\section{Material and methods}

The Autoregressive Moving Average (ARMA) process is given by

$$
\varphi_{p}(B) \dot{Z}_{z}=\theta_{q}(B) a_{t}
$$

Where

$$
\varphi_{p}(B)=1-\varphi_{1} B-\cdots-\varphi_{p} B^{p}
$$

And

$$
\theta_{q}(B)=1=\theta_{1} B=\theta_{2} B^{2}=\cdots=\theta_{q} B^{q}
$$

The stationary and invertible ARMA process can be written in pure autoregressive representation as,

$$
\pi(B) \dot{z}_{t}=a_{t}
$$


Where $\quad \pi(B)=\frac{\varphi_{p}(B)}{\theta_{q}(B)}=\left(1-\pi_{1} B-\pi_{2} B^{2}-\cdots\right)$

The process can also be written as a pure moving average representation as,

$$
\dot{z}_{2}=\varphi(B) a_{1}
$$

Where

$$
\varphi(B)=\frac{\theta_{q}(B)}{\varphi_{p}(B)}=\left(1+\varphi_{1} B+\varphi_{2} B^{2}+\cdots\right)
$$

To derive the autocovariance function, we write

$$
\bar{Z}_{z}=\varphi_{1} \dot{Z}_{t-1}+\cdots+\varphi_{p} \dot{Z}_{t-p}+a_{z}-\theta_{1} a_{t-1}=\cdots-\theta_{q} a_{t-q}
$$

and multiply both sides by $Z_{t-\hbar}$ and take expectation, i.e.,

$$
\begin{aligned}
& E\left(Z_{t} Z_{t-k}\right)= E\left[\varphi_{1} Z_{t-1} Z_{t-k}+\cdots+\varphi_{p} Z_{t-p} Z_{t-k}+a_{t} Z_{t-k}-\theta_{1} a_{t-1} Z_{t-k}-\cdots\right. \\
&\left.-\theta_{q} a_{t-q} Z_{t-k}\right] \\
& r_{\mathrm{s}}=\varphi_{1} \gamma_{k-1}+\cdots+\varphi_{p} \gamma_{k-p}+E\left(a_{t} Z_{t-k}\right)-\theta_{1} E\left(a_{t-1} Z_{t-k}\right)-m-\theta_{q} E\left(a_{t-q} Z_{t-k}\right.
\end{aligned}
$$

But; $\quad E\left(z_{t-k} a_{t-i}\right) \equiv \mathbf{0} \quad \forall k>i$

We have; $\quad \gamma_{k}=\varphi_{1} \gamma_{k-1}+{ }^{m}+\varphi_{p} \gamma_{k-p} \quad \forall k \geq(q+1)$

and hence; $\quad \rho_{k}-\varphi_{1} \rho_{k-1}+\cdots+\varphi_{p} \rho_{k-p} \quad \forall k \geq(q+1)$

The $p$ th order autoregressive process $A R(p)$ is

$$
\left(1-\varphi_{1} B-\varphi_{2} B^{2}-\cdots-\varphi_{p} B^{p}\right) \dot{Z}_{t}=a_{t}
$$

Or $\quad \dot{Z}_{z}=\varphi_{1} \dot{Z}_{t-1}+\varphi_{2} \dot{Z}_{t-2}+\cdots+\varphi_{p} \dot{Z}_{t-p}+a_{t}$

The moving average process of order q, denoted by $M A(q)$ is given by

$$
\bar{Z}_{t}=a_{t}-\theta_{1} a_{t-1}-\cdots-\theta_{q} a_{t-q}
$$

Or $\bar{z}_{t}=\theta(B) a_{i}$

Where $\theta(B)=\left(1-\theta_{1} B-\cdots-\theta_{q} B^{q^{2}}\right.$

Because $1+\theta_{1}^{2}+\cdots+\theta_{q}^{2}<\infty$, a finite moving average process is always stationary. This moving average is invertible if the roots of $\theta(B)=0$ lie outside of the unit circle. Moving average processes are useful in describing phenomena in which events produce an immediate effect that only lasts for short periods of time

\section{Results and Discussion}

All data were obtained from the Statistical Digest of Lagos State Bureau of Statistics for the period of 1991 to 2010. The original data are presented in Tables 1 and 2 while the corresponding forecasts are shown in Tables 3 and 4 for easy comparison. 
Table 1: Newly Registered Motor Vehicles by Type of Ownership and Year of Registration, Lagos, 1991-2010.

\begin{tabular}{|c|c|c|c|c|c|c|}
\hline $\begin{array}{c}\text { Type of } \\
\text { Ownership/ } \\
\text { Year }\end{array}$ & Private & Commercial & Government & $\begin{array}{c}\text { Mission/ } \\
\text { School }\end{array}$ & Corporation & Total \\
\hline $\mathbf{1 9 9 1}$ & 17559 & 4768 & 523 & 102 & 7751 & 30703 \\
\hline $\mathbf{1 9 9 2}$ & 27422 & 7959 & 860 & 474 & 6621 & 43336 \\
\hline $\mathbf{1 9 9 3}$ & 27169 & 11011 & 781 & 453 & 10227 & 49641 \\
\hline $\mathbf{1 9 9 4}$ & 26723 & 8204 & 257 & 131 & 8110 & 43425 \\
\hline $\mathbf{1 9 9 5}$ & 18862 & 4680 & 187 & 123 & 3702 & 27554 \\
\hline $\mathbf{1 9 9 6}$ & 21892 & 3616 & 131 & 134 & 2871 & 28644 \\
\hline $\mathbf{1 9 9 7}$ & 12205 & 1482 & 73 & 17 & 1234 & 15011 \\
\hline $\mathbf{1 9 9 8}$ & 10073 & 1057 & 87 & 53 & 1609 & 12879 \\
\hline $\mathbf{1 9 9 9}$ & 11260 & 1544 & 86 & 76 & 1890 & 14856 \\
\hline $\mathbf{2 0 0 0}$ & 25944 & 2270 & 204 & 105 & 3518 & 32041 \\
\hline $\mathbf{2 0 0 1}$ & 107555 & 13078 & 320 & 370 & 11773 & 133096 \\
\hline $\mathbf{2 0 0 2}$ & 121646 & 15651 & 373 & 419 & 12531 & 150620 \\
\hline $\mathbf{2 0 0 3}$ & 91669 & 9700 & 148 & 365 & 9951 & 111833 \\
\hline $\mathbf{2 0 0 4}$ & 53322 & 5879 & 216 & 258 & 7701 & 67376 \\
\hline $\mathbf{2 0 0 5}$ & 67246 & 5766 & 268 & 235 & 7563 & 81078 \\
\hline $\mathbf{2 0 0 6}$ & 109436 & 17446 & 571 & 332 & 13480 & 141265 \\
\hline $\mathbf{2 0 0 7}$ & 138592 & 19484 & 1061 & 1097 & 27208 & 187442 \\
\hline $\mathbf{2 0 0 8}$ & 181632 & 28425 & 651 & 843 & 28371 & 239922 \\
\hline $\mathbf{2 0 0 9}$ & 153781 & 32490 & 1170 & 890 & 22467 & 210798 \\
\hline $\mathbf{2 0 1 0}$ & 186429 & 32978 & 892 & 875 & 19789 & 240963 \\
\hline
\end{tabular}

Source: Source: Statistical Digest, Lagos State Bureau of Statistics, 2011.

Table 2:Newly Registered Motor Vehicles by Type of Vehicle and Year of Registration, Lagos, 19912010.

\begin{tabular}{|c|c|c|c|c|c|c|c|c|c|c|}
\hline $\begin{array}{c}\text { Type of } \\
\text { Vehicle s }\end{array}$ & $\begin{array}{c}\text { saloon/ } \\
\text { Wagon }\end{array}$ & Pick Up & $\begin{array}{c}\text { Lorry } \\
\text { /Truck }\end{array}$ & Minibu s & Ominibu s & Tanke r & Tracto r & Traile r & Tippe r & Total \\
\hline $\mathbf{1 9 9 1}$ & 23457 & 1512 & 421 & 4909 & 133 & 42 & 69 & 160 & & 30703 \\
\hline $\mathbf{1 9 9 2}$ & 33666 & 2078 & 863 & 5321 & 900 & 124 & 54 & 330 & & 43336 \\
\hline $\mathbf{1 9 9 3}$ & 36286 & 3608 & 1157 & 6682 & 1209 & 306 & 79 & 314 & & 49641 \\
\hline $\mathbf{1 9 9 4}$ & 31064 & 2327 & 960 & 7447 & 1369 & 157 & 45 & 56 & & 43425 \\
\hline $\mathbf{1 9 9 5}$ & 20249 & 1025 & 766 & 4941 & 527 & 18 & 23 & 5 & & 27554 \\
\hline $\mathbf{1 9 9 6}$ & 22082 & 1163 & 634 & 4138 & 605 & 3 & 6 & 13 & & 28644 \\
\hline $\mathbf{1 9 9 7}$ & 12511 & 345 & 237 & 1580 & 305 & 9 & 16 & 8 & & 15011 \\
\hline $\mathbf{1 9 9 8}$ & 10529 & 367 & 358 & 1573 & 36 & 5 & 5 & 6 & & 12879 \\
\hline $\mathbf{1 9 9 9}$ & 12104 & 361 & 344 & 1920 & 98 & 7 & 13 & 9 & & 14856 \\
\hline $\mathbf{2 0 0 0}$ & 27729 & 341 & 494 & 3175 & 256 & 1 & 29 & 16 & & 32041 \\
\hline $\mathbf{2 0 0 1}$ & 112600 & 1269 & 4016 & 14529 & 552 & 16 & 41 & 53 & 20 & 133096 \\
\hline $\mathbf{2 0 0 2}$ & 127446 & 1876 & 4791 & 15469 & 833 & 12 & 46 & 88 & 59 & 150620 \\
\hline $\mathbf{2 0 0 3}$ & 95326 & 1523 & 3526 & 10897 & 366 & 2 & 42 & 96 & 55 & 111833 \\
\hline $\mathbf{2 0 0 4}$ & 57826 & 1146 & 1723 & 6292 & 202 & 6 & 25 & 70 & 86 & 67376 \\
\hline $\mathbf{2 0 0 5}$ & 70496 & 1460 & 1780 & 6988 & 162 & 16 & 17 & 49 & 110 & 81078 \\
\hline $\mathbf{2 0 0 6}$ & 118099 & 3616 & 4175 & 14290 & 485 & 30 & 50 & 216 & 304 & 141265 \\
\hline $\mathbf{2 0 0 7}$ & 156858 & 6149 & 6357 & 17124 & 116 & 61 & 73 & 172 & 532 & 187442 \\
\hline $\mathbf{2 0 0 8}$ & 202042 & 7084 & 9987 & 19244 & 392 & 94 & 77 & 157 & 845 & 239922 \\
\hline $\mathbf{2 0 0 9}$ & 166207 & 6995 & 1329 & 22351 & 434 & 83 & 81 & 322 & 1029 & 210798 \\
\hline $\mathbf{2 0 1 0}$ & 188515 & 7203 & 11690 & 30232 & 1541 & 40 & 97 & 782 & 863 & 240963 \\
\hline
\end{tabular}

Source: Statistical Digest, Lagos State Bureau of Statistics, 2011. 
The data obtained were inputted into statistical software, MINITAB, for the indicated period and several analysis were done using the package.

After several iteration of autocorrelation, each of the fourteen variables produced models that conformed to one of the three models which are: Autocorrelation, (AR) Moving Average (MA) or both i.e. (ARMA)

$\mathrm{AR}$ is of the form

$$
\mathrm{X}_{\mathrm{t}}=\phi \mathrm{X}_{\mathrm{t}-1}+\epsilon_{\mathrm{t}}
$$

MA is of the form

ARMA is of the form

$$
\mathrm{X}_{\mathrm{t}}=\epsilon_{\mathrm{t}}-\Theta_{1} \epsilon_{\mathrm{t}-1}+\Theta_{2} \epsilon_{\mathrm{t}-2}
$$

$$
\mathrm{X}_{\mathrm{t}}-\phi \mathrm{X}_{\mathrm{t}-1}-\phi \mathrm{X}_{\mathrm{t}-2}=\epsilon_{\mathrm{t}}-\Theta_{1 \epsilon_{\mathrm{t}-1}}+\Theta_{2} \epsilon_{\mathrm{t}-2}
$$

Those variables that produced ARMA are Private (Ownership of Vehicles), Tanker, Tractor and Tipper (Types of Vehicles). Those that produced AR include: Commercial, Government, Corporation, (Ownership of Vehicles), Saloon, Minibus, Omnibus and Trailer (Types of Vehicles) while those that produced MA are Mission/School ( Ownership of Vehicles) Pick Up and Lorry/Truck (Types of Vehicles ).

The models obtained using MINITAB Package for the Motor Vehicle registration by Ownership are as indicated below and following these, is the table indicating their Four years (Y2011 Y2014) Forecast.

\section{PRIVATE ( ARMA)}

$$
\mathrm{X}_{\mathrm{t}}+0.4973 \mathrm{X}_{\mathrm{t}-1}+0.1081 \mathrm{X}_{\mathrm{t}-2}=\epsilon_{\mathrm{t}}-0.4211 \epsilon_{\mathrm{t}-1}-1.148 \epsilon_{\mathrm{t}-2}
$$

The ARMA $(2,2)$ was obtained and the forecast shows that there is likely to be future increase in the number of private vehicles to be registered.

\section{COMMERCIAL ( AR)}

$$
\mathrm{X}_{\mathrm{t}}=0.2481 \mathrm{X}_{\mathrm{t}-1}
$$

The AR (1) was obtained and the forecast shows that there is likely to be future increase in the number of commercial vehicles to be registered.

\section{GOVERNMENT ( AR )}

$$
\mathrm{X}_{\mathrm{t}}=0.7317 \mathrm{X}_{\mathrm{t}-1}
$$

The AR (1) was obtained and the forecast shows that there is likely to be future increase in the number of government vehicles to be registered. The reason for this is government's involvement in the purchase of red buses and blue buses for BRT and LAGBUS Schemes. This is made possible as more routes will be targeted.

\section{MISSION/SCHOOL (MA)}

$$
\mathrm{X}_{\mathrm{t}}=\epsilon_{\mathrm{t}}+0.6620 \epsilon_{\mathrm{t}-1}
$$

The MA (1) was obtained and the forecast shows that there is likely to be future decrease in the number of mission/school vehicles to be registered. This reason for this, is probably the manual capture of vehicle registration pre the introduction of AUTOREG Platform in Lagos State. 


\section{CORPORATION (AR)}

$$
\mathrm{X}_{\mathrm{t}} \quad=0.4870 \mathrm{X}_{\mathrm{t}-1}-0.5679 \mathrm{X}_{\mathrm{t}-2}
$$

The AR (2) was obtained and the forecast shows that there is likely to be future increase in the number of corporation vehicles to be registered. This can be adduced to the state of the economic. It has been predicted that the economy of Nigeria will thrive as the years come by and so more company and corporation are likely to spring up and movement will be imminent.

TABLE 3 TABLE OF FORECAST OF MOTOR VEHICLES REGISTRATION BY OWNERSHIP (2011-2014)

\begin{tabular}{|c|c|c|c|c|c|}
\hline YEAR & OWNERSHIP & $\mathbf{2 0 1 1}$ & $\mathbf{2 0 1 2}$ & $\mathbf{2 0 1 3}$ & $\mathbf{2 0 1 4}$ \\
\hline FORECAST & Private & 237663 & 246837 & 276354 & 301737 \\
\hline & Commercial & 34224 & 35659 & 37140 & 38633 \\
\hline & Government & 787 & 710 & 653 & 612 \\
\hline & Mission/School & 471 & 364 & 364 & 364 \\
\hline & Corporation & 22659 & 26400 & 27413 & 26604 \\
\hline LOWER & Private & 18133 & 169459 & 196653 & 221684 \\
\hline & Commercial & 24837 & 20646 & 17736 & 15585 \\
\hline & Government & 284 & 87 & 0 & 0 \\
\hline & Mission/School & 0 & 0 & 0 & 0 \\
\hline & Corporation & 14944 & 12575 & 10960 & 9242 \\
\hline & Private & 290192 & 324215 & 356055 & 381789 \\
\hline & Commercial & 43612 & 50672 & 56545 & 61681 \\
\hline & Government & 1289 & 1332 & 1331 & 1318 \\
\hline & Mission/School & 964 & 956 & 956 & 956 \\
\hline & Corporation & 30374 & 40225 & 43866 & 43966 \\
\hline
\end{tabular}

The models obtained using Minitab Package for the Motor Vehicle registration by Type are as indicated below and following these, is the table indicating their Four years (Y2011 - Y2014) Forecast.

\section{SALOON/ WAGON (AR)}

$$
\mathrm{X}_{\mathrm{t}}=0.3290 \mathrm{X}_{\mathrm{t}-1}
$$

The ARMA (1) was obtained and the forecast shows that there is likely to be future increase in the number of saloon/wagon vehicles to be registered. As the economic improves, the quest to own one's car increases and so this might be the reason for the future increase in the registration of salon / wagon cars.

\section{PICK UP (ARMA)}

$$
X_{t}=0.8208 X_{t-1}-1.1339 \epsilon_{t}+\epsilon_{\mathrm{t}}
$$

The ARMA $(1,1)$ was obtained and the forecast shows that there is likely to be future increase in the number of private vehicles to be registered. This reason for this, is probably the manual capture of vehicle registration pre the introduction of AUTOREG Platform in Lagos State. 


\section{LORRY/TRUCK (MA)}

$$
\mathrm{X}_{\mathrm{t}}=\epsilon_{\mathrm{t}}-0.2147 \epsilon_{\mathrm{t}-1}-0.6390 \epsilon_{\mathrm{t}-2}
$$

The MA (2) was obtained and the forecast shows that there is likely to be future increase in the number of lorry/truck vehicles to be registered. Business is likely to boom and so there is need to convey goods from one point to another.

\section{MINIBUS (AR)}

$$
\mathrm{X}_{\mathrm{t}}=0.3258 \mathrm{X}_{\mathrm{t}-1}
$$

The AR (1) was obtained and the forecast shows that there is likely to be future increase in the number of minibus vehicles to be registered. Likely increase because they cover routes that the BRT and LAGBUS cannot cover.

\section{OMINIBUS (AR)}

$$
\mathrm{X}_{\mathrm{t}} \quad=0.7317 \mathrm{X}_{\mathrm{t}-1}+0.3679 \mathrm{X}_{\mathrm{t}-2}
$$

The AR (2) was obtained and the forecast shows that there is likely to be future increase in the number of Omnibus Vehicles to be registered. This is because Lagos is the economic hub of Nigeria and vibrant in economic activities, hence the inflow of luxury buses into Lagos.

\section{TANKER (ARMA)}

$$
\mathrm{X}_{\mathrm{t}}-1.1882 \mathrm{X}_{\mathrm{t}-1}+0.4369 \mathrm{X}_{\mathrm{t}-2}=\epsilon_{\mathrm{t}}-0.2674 \epsilon_{\mathrm{t}-1}-0.6420 \epsilon_{\mathrm{t}-2}
$$

The ARMA $(2,2)$ was obtained and the forecast shows that there is likely to be future decrease in the number of tanker vehicles to be registered. In the future, there is likely usage of pipe line and trains which are better alternatives to tankers.

\section{TRACTOR (ARMA)}

$$
\mathrm{X}_{\mathrm{t}}-0.7259 \mathrm{X}_{\mathrm{t}-1}=\epsilon_{\mathrm{t}}+0.3392 \epsilon_{\mathrm{t}-1}+0.1682 \epsilon_{\mathrm{t}-2}
$$

The ARMA $(1,2)$ was obtained and the forecast shows that there is likely to be future increase in the number of PrivateTractors to be registered. To reverse this future trend, government should invest more in agriculture and encourage more people to invest in the construction industry.

\section{TRAILER (AR)}

$$
\mathrm{X}_{\mathrm{t}} \quad=1.5363 \mathrm{X}_{\mathrm{t}-1} \quad-0.7229 \mathrm{X}_{\mathrm{t}-2}
$$

The AR (2) was obtained and the forecast shows that there is likely to be future increase in the number of private vehicles to be registered. Business is likely to boom and so there is need to convey goods from one point to another. 


\section{TIPPER (ARMA)}

$$
\mathrm{X}_{\mathrm{t}}-1.6416 \mathrm{X}_{\mathrm{t}-1}+1.0233 \mathrm{X}_{\mathrm{t}-2}=\epsilon_{\mathrm{t}}+0.7348 \epsilon_{\mathrm{t}-1}+0.8359 \epsilon_{\mathrm{t}-2}
$$

The ARMA $(2,2)$ was obtained and the forecast shows that there is likely to be future decrease in the number of private vehicles to be registered. This can be adduced by the fact that there were no figures for pre 2001.

TABLE 4 TABLE OF FORECAST OF MOTOR VEHICLES REGISTRATION BY TYPE

(2011-2014)

\begin{tabular}{|c|c|c|c|c|c|}
\hline YEAR & TYPE & $\mathbf{2 0 1 1}$ & $\mathbf{2 0 1 2}$ & $\mathbf{2 0 1 3}$ & $\mathbf{2 0 1 4}$ \\
\hline FORECAST & Saloon/Wagon & 19249 & 19414 & 19809 & 20280 \\
\hline & Pick-Up & 7158 & 6427 & 5827 & 5334 \\
\hline & Lorrv/Truck & 10596 & 11766 & 12994 & 14273 \\
\hline & Minibus & 33790 & 35940 & 37630 & 39172 \\
\hline & Omnibus & 1308 & 731 & 394 & 360 \\
\hline & Tanker & 27 & 36 & 41 & 44 \\
\hline & Tractor & 94 & 87 & 78 & 72 \\
\hline & Trailer & 1009 & 1024 & 885 & 659 \\
\hline \multirow{2}{*}{ LOWER } & Tipper & 341 & 0 & 0 & 0 \\
\hline & Saloon/Wagon & 10431 & 4748 & 426 & 0 \\
\hline & Pick-Up & 5723 & 3276 & 1924 & 998 \\
\hline & Lorry/Truck & 7415 & 5258 & 4042 & 3147 \\
\hline & Minibus & 26014 & 23026 & 20578 & 18658 \\
\hline & Omnibus & 530 & 0 & 0 & 0 \\
\hline & Tanker & 0 & 0 & 0 & 0 \\
\hline & Tractor & 59 & 35 & 17 & 6 \\
\hline & Trailer & 746 & 543 & 240 & 0 \\
\hline & Tipper & 216 & 0 & 0 & 0 \\
\hline UPPER & Saloon/Wagon & 28067 & 34079 & 39191 & 43612 \\
\hline & Pick-Up & 8593 & 9578 & 9729 & 9670 \\
\hline & Lorry/Truck & 13777 & 18274 & 21942 & 25398 \\
\hline & Minibus & 41567 & 48854 & 54683 & 59687 \\
\hline & Omnibus & 2086 & 1695 & 1367 & 1340 \\
\hline & Tanker & 135 & 182 & 188 & 197 \\
\hline & Tractor & 129 & 138 & 139 & 137 \\
\hline & Trailer & 1271 & 1505 & 1530 & 1401 \\
\hline & Tipper & 466 & 0 & 0 & 0 \\
\hline
\end{tabular}

The ARMA $(2,2)$ was obtained and the forecast shows that there is likely to be future decrease in the number of private vehicles to be registered. This can be adduced by the fact that there were no figures for pre 2001. A sample on the Chart of the Partial Autocorrelation Function for Private vehicles as revealed in equation 12 is shown below.

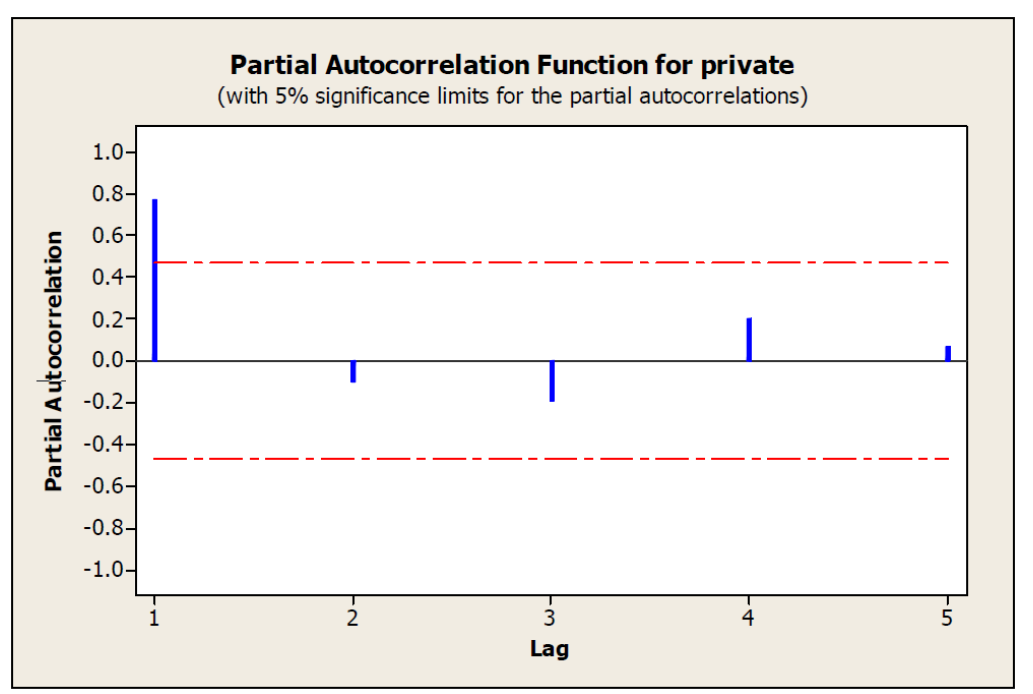




\section{Conclusion}

This research work is an attempt to select the best and accurate model among various ARMA estimated models which posses' high power of predictability (forecasting power). We have identified a framework for ARMA modeling which includes the following steps: data collection and examination; determining the order of integration; model identification; diagnostic checking; model stability testing; and forecast performance evaluation. We have adopted the traditional BoxJenkins approach of forecasting known as ARMA modeling, in which a time series is expressed in terms of past values of itself (the autoregressive component) plus current and lagged values of a 'white noise' error term (the moving average component). The primary purpose behind this study was to find out which ARMA model is more accurate and appropriate for forecasting purposes in transportation system especially the Vehicular registration in Lagos State of Nigeria by keeping in view the cost of model building.

A general rule of thumb for univariate forecasting is to test, test and test at all stages of the ARMA process. ARMA models are theoretically justified and can be surprisingly robust with respect to alternative (multivariate) modeling approaches.

The study is based on yearly vehicle registration in Lagos State, which was used to estimate various possible ARMA models. Among these estimated models, the best model for vehicle registration forecast for the period 2011 to 2014 have been obtained. The comparative performance of these ARMA models have been checked and verified by using the statistics, MAPE. The comparison indicates that the best ARMA model (1) performs much better than the rest of the estimated models.

\section{References}

[1] Batchelor R, Alizadeh A, Visvikis I (2007). Forecasting spot and forward prices in the international freight market. Int. J. Forecasting., 23(1): 101-114.

[2] Box GEP, Jenkins GM (1976). Time Series Analysis: Forecasting and Control. San Francisco: Holden-Day Inc.

[3] Box GEP, Jenkins GM, Reinsel GC (1994). Time Series Analysis: Forecasting and control. 3rd edition, Prentice Hall: Englewood Cliffs, New Jersey.

[4] Box GEP, Tiao GC (1975). Intervention analysis with applications to economic and environmental problems. J. Am. Stat. Assoc., 70: 70-74.

[5] Coshall JT (2003). The threat of terrorism as an intervention on international travel flows. J. Travel. Res., 42(1): 4-12.

[6] Karlaftis MG, Vlahogianni EI (2009). Memory properties and fractional integration in transportation time-series. Transport Res C-Emer, 17(4): 444-453.

[7] Lai SL, Lu WL (2005). Impact analysis of September 11 on air travel demand in the USA. J. Air. Transp. Manage., 11(6): 455-458.

[8] Lim C, McAleer M (2002). Time series forecasts of international travel demand for Australia. Tourism Manage., 23(4): 389-396.

[9] Inglada and Rey, 2004,

[10]McLeod and Vingilis, 2008,

[11]Liu LM (2006). Time Series Analysis and Forecasting. $2^{\text {nd }}$ edition, Scientific Computing Associations Corp. 